\title{
OPEN Platelet-to-lymphocyte ratio is not a predictor of clinically significant prostate cancer at the prostate biopsy: A large cohort study
}

\begin{abstract}
Jeong Woo Lee ${ }^{1}$, Hyeon Jeong ${ }^{2}$, Hwancheol Son ${ }^{2} \&$ Min Chul Cho ${ }^{2 \bowtie}$
Previous studies have reported conflicting results on the predictive role of the platelet-to-lymphocyte ratio (PLR) in detecting clinically significant prostate cancer (CSPCa) at the time of prostate biopsies. We explored the predictive value of pre-biopsy PLRs for CSPCa using our large-cohort database. Consecutive men with serum prostate-specific antigen (PSA) levels of $\geq 3.0 \mathrm{ng} / \mathrm{mL}$ or abnormal digital rectal examination (DRE) findings and who underwent prostate biopsies were included in the study. There was no significant difference in the pre-biopsy PLR between men with benign disease, clinically insignificant prostate cancer (CISPCa), and CSPCa. Only the subset of CSPCa patients with serum PSA levels of $<10 \mathrm{ng} / \mathrm{mL}$ showed lower PLRs than those with benign disease or CISPCa. In the entire patient cohort, multivariate analyses revealed that older age, diabetes mellitus, DRE abnormalities, higher serum PSA levels, and smaller prostate volume were predictors of CSPCa. However, the pre-biopsy PLR was not a significant predictor of CSPCa at the prostate biopsy in the entire patient cohort or the subset of patients with serum PSA levels of $<10 \mathrm{ng} / \mathrm{mL}$. In summary, the pre-biopsy PLR is not an independent predictor of CSPCa at the prostate biopsy, regardless of the serum PSA level.
\end{abstract}

Recently, prostate cancer (PCa) has been ranked as the second most frequent cancer and the fifth leading cause of cancer death in men $^{1}$. For decades, the widespread use of prostate-specific antigen (PSA) screening has been associated with a significant decline in the incidence of advanced PCa and, thereby, a reduction in PCa-specific mortality ${ }^{2}$. However, there have been growing concerns about overdiagnosis and overtreatment because of the increased detection of clinically insignificant prostate cancer (CISPCa) in previously unscreened men ${ }^{2,3}$. Therefore, given that PSA is not cancer-specific and has a low positive predictive value of less than $25.0 \%$ for the detection of $\mathrm{PCa}^{4}$, there is a need for identifying useful markers as adjuncts to serum PSA levels for predicting clinically significant cancers, which thereby, can reduce the number of unnecessary prostate biopsies.

Under this background, magnetic resonance imaging (MRI), blood-based biomarkers (Prostate Health Index and the four-kallikrein score), urine-based biomarkers (PCA-3), positron emission tomography imaging using radiopharmaceuticals, and a few risk calculators (SelectMDx and the Stockholm-3 model) have been introduced to improve the accuracy of serum PSA levels in detecting clinically significant cancers before prostate biopsy ${ }^{5,6}$. However, their routine use before prostate biopsy cannot be generalized in real clinical practice due to limitations such as high cost, availability issues, and problems with insurance coverage. Thus, it is important to identify meaningful predictors of clinically significant cancers that are readily available in real clinical practice.

Recent evidence has suggested that inflammation is involved in tumorigenesis and the progression of $\mathrm{PCa}^{7,8}$. Also, a recent meta-analysis showed that systemic inflammatory markers such as the platelet-to-lymphocyte ratio (PLR), which could be easily calculated from the complete blood count (CBC), were associated with the prognosis of men with $\mathrm{PCa}^{9}$. In this context, a minority of studies of small or medium-sized cohorts have tested the predictive role of PLR in detecting clinically significant cancers at the time of prostate biopsies but reported conflicting results $^{10-14}$. Therefore, we aimed to determine if the pre-biopsy PLR would predict clinically significant prostate

\footnotetext{
${ }^{1}$ Department of Urology, Kyung Hee University Medical Center, Kyung Hee University College of Medicine, Seoul, Korea. ${ }^{2}$ Department of Urology, Seoul Metropolitan Government-Seoul National University Boramae Medical Center, 20, Boramae-ro 5-Gil, Gongjak-gu, Seoul 156-707, Korea. ${ }^{\square}$ email: cmc1206@empas.com
} 
cancers (CSPCa) at the time of the standard 12-core transrectal ultrasound-guided prostate biopsy (TRUS-Bx), currently the reference standard for the diagnosis of $\mathrm{PCa}$, using our large cohort data.

\section{Materials and methods}

Subjects and research design. Between October 2010 and January 2020, a total of 1652 men who underwent standard 12-core TRUS-Bxs due to serum PSA levels of $\geq 3.0 \mathrm{ng} / \mathrm{mL}$ or abnormal DRE findings without the following exclusion criteria were included in the analysis of the present study. The exclusion criteria included retrieved biopsy cores of less than 12 and incomplete peri-biopsy data. The patients underwent pre-biopsy evaluations that included medical history, DRE, blood tests (CBC, blood urea nitrogen, creatinine, aspartate aminotransferase, alanine aminotransferase, prothrombin time, activated partial thromboplastin time, and PSA and testosterone levels), and urinalysis. The prospectively collected database was retrospectively analyzed in our study. The present study was approved by the SMG-SNU* Boramae Medical Center Institutional Review Board and followed the provisions of the Declaration of Helsinki (revised, Edinburgh 2000). This study is based only on retrospective analysis of clinical records of patients, and there is no minimum risk to patients during the study. Therefore, this study was exempted from obtaining informed consent after IRB review.

Standard transrectal ultrasound-guided prostate biopsy and pathological data. The standard 12 -core TRUS-Bx was performed in a routine manner, as described previously ${ }^{15}$. Briefly, after the patients laid on their side with their knees pulled up to their chest, they received local anesthesia using a periprostatic neurovascular bundle block. Biopsy tissue samples were collected using an automatic spring-propelled biopsy gun with an 18-G 22-mm core biopsy needle. A systematic 12-core biopsy scheme including the prostate apex and bilateral far lateral peripheral zones was used for the standard TRUS-Bxs. When some lesions on TRUS were suspicious of cancer, one or two biopsy samples were additionally collected.

The biopsy specimens were evaluated by uropathologists, and the Gleason grade groups or Gleason scores were determined according to the 2014 International Society of Urological Pathology classification (ISUP) ${ }^{16}$. The maximum percentage of cancer involvement and the number of biopsy cores positive for cancer were determined.

Evaluation parameters and definitions. We defined clinically significant prostate cancer as Gleason grade groups of 2 or higher. The PLR was defined as the ratio of the platelet count to the absolute lymphocyte count, as follows: the platelet count/the absolute lymphocyte count. The prostate volumes on TRUS were measured tri-dimensionally in the following manner (the prolate ellipsoid formula): $\pi / 6 \times$ transverse dimension (width) $\times$ anteroposterior dimension (length) $\times$ vertical dimension (height).

Data analyses. Statistical comparisons between the continuous variables were performed using the independent t-test or the one-way analysis of variance (ANOVA) test for normally distributed data and the MannWhitney U test or the Kruskal-Wallis test for skewed data. For the categorical variables, statistical comparisons were performed using Fisher's exact test or the $\chi^{2}$ test. To determine if PLR was a significant predictor of CSPCa, logistical regression analysis was performed with adjustments for explanatory variables such as age, body mass index (BMI), the presence or absence of diabetes mellitus (DM), the presence or absence of DRE abnormalities, serum PSA levels, serum testosterone levels, and prostate volume on TRUS. Statistical significance was defined as a p-value of $<0.05$. The data analyses were conducted using SPSS Version 20.0 (SPSS Inc., Chicago, USA).

\section{Results}

Comparison of patient characteristics according to pre-biopsy serum PSA levels. Table 1 shows a comparison of the peri-biopsy data of the eligible patients according to serum PSA levels before the biopsy. The patients with higher serum PSA levels had older age, a higher rate of DRE abnormalities, a higher rate of prostate cancer or clinically significant cancer detection, a higher number of biopsy cores positive for cancer, and a greater maximum percentage of cancer infiltration in the biopsy cores that those with lower serum PSA levels. The patients with serum PSA levels of $\geq 20 \mathrm{ng} / \mathrm{mL}$ showed a higher prevalence of hypertension and lower serum testosterone levels compared to those with serum PSA levels of $<20 \mathrm{ng} / \mathrm{mL}$ and those with serum PSA levels of $<10 \mathrm{ng} / \mathrm{mL}$, respectively. The patients with serum PSA levels of $\geq 10 \mathrm{ng} / \mathrm{mL}$ showed a higher pre-biopsy PLR and a larger prostate volume than those with serum PSA levels of $<10 \mathrm{ng} / \mathrm{mL}$.

Only the subset of patients with serum PSA levels of $<10 \mathrm{ng} / \mathrm{mL}$ with clinically significant cancer had lower levels of PLR than those with clinically insignificant cancer or benign disease. A comparison of the explanatory variables between men with benign prostatic disease, clinically insignificant cancer, and clinically significant cancer is shown in Table 2. In the entire patient cohort, the patients with clinically significant cancer had older age, a higher rate of DRE abnormalities, higher serum PSA levels, and lower serum testosterone levels than those with clinically insignificant cancer or benign disease. However, there was no significant difference in the pre-biopsy PLR among the three groups. In a subset of patients with serum PSA levels of $<10 \mathrm{ng} / \mathrm{mL}$, the patients with clinically significant cancer showed lower PLRs than those with clinically insignificant cancer or benign disease. In the subset of patients with serum PSA levels between $10 \mathrm{ng} / \mathrm{mL}$ and $20 \mathrm{ng} / \mathrm{mL}$, the patients with clinically significant cancer showed lower serum testosterone levels and smaller prostatic volumes than those with clinically insignificant cancer or benign disease. However, there were no significant differences in pre-biopsy PLRs or serum PSA levels between the three groups. In the subset of patients with serum PSA levels of $\geq 20 \mathrm{ng} / \mathrm{mL}$, the patients with clinically significant cancer showed a higher 


\begin{tabular}{|c|c|c|c|c|c|}
\hline Variables & All patients $(n=1652)$ & PSA $<10(n=1072)$ & $10 \leq$ PSA $<20(n=344)$ & PSA $\geq 20(n=236)$ & p-value \\
\hline \multicolumn{6}{|c|}{ Median (interquartile range) or number of patients (\%) } \\
\hline Age, yr & $68.0(62.0-73.0)$ & $66.0(61.0-71.0)$ & $69.0(63.0-74.0)^{\dagger}$ & $72.0(66.3-76.0)^{\dagger \ddagger}$ & $<0.001$ \\
\hline BMI, $\mathrm{kg} / \mathrm{m}^{2}$ & $24.04(22.28-25.86)$ & $24.16(22.55-26.00)$ & $23.86(22.16-25.64)^{\dagger}$ & $23.90(21.45-25.77)$ & 0.041 \\
\hline DM & $282(17.1 \%)$ & $169(15.8 \%)$ & $64(18.6 \%)$ & $49(17.1 \%)$ & 0.126 \\
\hline HTN & $711(43.0 \%)$ & $435(40.6 \%)$ & $150(43.6 \%)$ & $126(53.4 \%)^{\dagger \dagger \ddagger}$ & 0.002 \\
\hline DRE abnormality & $281(17.0 \%)$ & $123(11.5 \%)$ & $70(20.3 \%)^{\dagger}$ & $88(37.3 \%)^{\dagger \ddagger}$ & $<0.001$ \\
\hline PSA, ng/mL & $7.72(5.07-13.39)$ & $5.83(4.26-7.52)$ & $13.48(11.34-16.24)^{\dagger}$ & $43.70(28.10-94.30)^{\dagger \neq}$ & $<0.001$ \\
\hline Serum testosterone, $\mathrm{ng} / \mathrm{mL}$ & $4.22(3.36-5.56)$ & $4.26(3.41-5.66)$ & $4.20(3.49-5.54)$ & $3.89(2.94-5.56)^{\dagger}$ & 0.058 \\
\hline Serum creatinine, $\mathrm{mg} / \mathrm{dL}$ & $0.92(0.82-1.04)$ & $0.92(0.82-1.03)$ & $0.94(0.81-1.05)$ & $0.92(0.82-1.09)$ & 0.479 \\
\hline $\begin{array}{l}\text { Platelet-to-lymphocyte } \\
\text { ratio }\end{array}$ & $0.115(0.093-0.145)$ & $0.114(0.093-0.141)$ & $0.120(0.092-0.153)^{\dagger}$ & $0.118(0.097-0.152)^{\dagger}$ & 0.008 \\
\hline Total prostate volume, $\mathrm{mL}$ & $38.0(28.7-52.0)$ & $37.0(28.0-48.0)$ & $42.0(29.6-62.1)^{\dagger}$ & $41.1(30.7-57.9)^{\dagger}$ & $<0.001$ \\
\hline $\begin{array}{l}\text { Prostate cancer, GS } \\
\text { grouping }\end{array}$ & $540(32.7 \%)$ & $243(22.7 \%)$ & $125(36.3 \%)^{\dagger}$ & $172(72.9 \%)^{\dagger \neq}$ & $<0.001$ \\
\hline GS $6(3+3)$ & $173(10.5 \%)$ & $123(11.5 \%)$ & $37(10.8 \%)$ & $13(5.5 \%)$ & \\
\hline GS $7(3+4)$ & $90(5.4 \%)$ & $40(3.7 \%)$ & $31(9.0 \%)$ & $19(8.1 \%)$ & \\
\hline GS $7(4+3)$ & $93(5.6 \%)$ & $41(3.8 \%)$ & $24(7.0 \%)$ & $28(11.9 \%)$ & \\
\hline GS 8 & $113(6.8 \%)$ & $29(2.7 \%)$ & $23(6.7 \%)$ & $61(25.8 \%)$ & \\
\hline GS 9 or 10 & $71(4.3 \%)$ & $10(0.9 \%)$ & $10(2.9 \%)$ & $51(21.6 \%)$ & \\
\hline $\begin{array}{l}\text { Clinically significant pros- } \\
\text { tate cancer }\end{array}$ & $367(22.2 \%)$ & $120(11.2 \%)$ & $88(25.6 \%)^{\dagger}$ & $159(67.4 \%)^{\dagger \ddagger}$ & $<0.001$ \\
\hline No. of positive cancer cores & $4(2-7)$ & $3(1-4)$ & $4(2-6)^{\dagger}$ & $8(6-11)^{\dagger+}$ & $<0.001$ \\
\hline $\begin{array}{l}\text { Maximum percentage of } \\
\text { cancer involvement in } \\
\text { biopsy cores, } \%\end{array}$ & $43.4(22.3-65.2)$ & $44.8(17.8-64.3)$ & $37.5(23.1-50.0)$ & $70.6(43.8-100.0)^{\dagger \ddagger}$ & 0.010 \\
\hline
\end{tabular}

Table 1. Baseline characteristics of men who underwent standard 12-core TRUS-Bxs. BMI body mass index, $D M$ diabetes mellitus, $H T N$ hypertension, DRE digital rectal examination, PSA prostate-specific antigen, GS Gleason score, No. number, $y r$ years. ${ }^{*} \mathrm{p}<0.05$ : comparison of the variables between the groups using the Kruskal-Wallis test, the chi-squared test, or Fisher's exact test, as indicated. ${ }^{\dagger} \mathrm{p}<0.05$ : compared to the group with PSA $<10$ using the Mann-Whitney $U$ test, the chi-squared test, or Fisher's exact test, as indicated. ${ }^{\ddagger} \mathrm{p}<0.05$ : comparison between the groups with $10 \leq \mathrm{PSA}<20$ and PSA $\geq 20$ using the Mann-Whitney $\mathrm{U}$ test, the chi-squared test, or Fisher's exact test, as indicated.

rate of DRE abnormalities and higher serum PSA levels than those with clinically insignificant cancer or benign disease. However, there was no difference in the pre-biopsy PLRs between the three groups.

Pre-biopsy PLR was not a predictor of clinically significant prostate cancer at the standard 12-core TRUS-BX. Univariate and multivariate logistic regression analyses were performed to determine whether the pre-biopsy PLR predicted CSPCa at the standard 12-core TRUS-Bx. In the entire patient cohort, the logistic regression analysis showed that the pre-biopsy PLR was not a significant predictor of CSPCa at the prostate biopsy (Table 3). Instead, older age, the presence of DM, the presence of DRE abnormalities, higher serum PSA levels, and smaller prostate volume were predictors of clinically significant cancer. In the subset of patients with serum PSA levels of $<10 \mathrm{ng} / \mathrm{mL}$, the multivariate regression model showed that older age, the presence of DM, higher serum PSA levels, and smaller prostate volumes were predictive factors of clinically significant cancer, whereas the pre-biopsy PLR was not. In the subset of patients with serum PSA levels between $10 \mathrm{ng} / \mathrm{mL}$ and $20 \mathrm{ng} / \mathrm{mL}$, older age, lower serum testosterone levels, and smaller prostate volume were predictors of clinically significant cancers, whereas the PLR was not. In the subset of patients with serum PSA levels of $\geq 20 \mathrm{ng} /$ $\mathrm{mL}$, older age, the presence of DRE abnormalities, higher serum PSA levels, and smaller prostate volume were predictive factors of clinically significant cancers but the pre-biopsy PLR was not.

\section{Discussion}

The association between inflammation and cancer is still controversial. Most solid tumors have complex hosttumor relationships with inflammatory cells and mediators in the microenvironment ${ }^{17}$. In contrast, a review article on cancer immunology stated that inflammation and the immune system had inhibitory effects on carcinogenesis through tumor-related and tumor-specific antigen reactions ${ }^{18}$. A meta-analysis demonstrated that high PLRs, a marker of inflammation, led to the progression and poor prognosis of patients with various kinds of solid tumors, such as colorectal, hepatocellular, gastroesophageal, ovarian, and pancreatic cancer ${ }^{19}$. Platelets, perhaps through their ligands, interact with tumor cells or promote tumor cell adherence to the microvascular endothelium, allowing tumor cells to evade host immunosurveillance ${ }^{20,21}$. Lymphocytes regulate antitumor activity through host immune responses by inhibiting tumor proliferation and migration by secreting cytokines, such as TNF- $\alpha$ and INF- $\gamma$, and inducing cytotoxic apoptosis ${ }^{22}$. Based on these basic studies, it can be understood 


\begin{tabular}{|c|c|c|c|c|}
\hline \multirow[b]{2}{*}{ All patients } & \multirow{2}{*}{$\begin{array}{l}\text { Benign disease } \\
(\mathrm{n}=1112)\end{array}$} & \multirow{2}{*}{$\begin{array}{l}\text { Clinically insignificant cancer } \\
(\mathbf{n}=173)\end{array}$} & \multirow{2}{*}{$\begin{array}{l}\text { Clinically significant cancer } \\
(\mathrm{n}=367)\end{array}$} & \multirow[b]{2}{*}{ p-value ${ }^{*}$} \\
\hline & & & & \\
\hline \multicolumn{5}{|c|}{ Median (interquartile range) or number of patients (\%) } \\
\hline Age, yr & $66.0(61.0-71.0)$ & $69.0(63.0-74.0)^{\dagger}$ & $71.0(67.0-76.0)^{\dagger+}$ & 0.001 \\
\hline Body mass index, $\mathrm{kg} / \mathrm{m}^{2}$ & $24.0(22.4-25.9)$ & $24.3(22.0-26.2)$ & $23.9(22.0-25.7)$ & 0.243 \\
\hline Diabetes mellitus & $171(15.4 \%)$ & $32(18.5 \%)$ & $79(21.5 \%)^{\dagger}$ & 0.022 \\
\hline Abnormal DRE finding & $131(11.8 \%)$ & $25(14.5 \%)$ & $125(34.1 \%)^{\dagger *}$ & $<0.001$ \\
\hline PSA, ng/mL & $6.72(4.54-10.07)$ & $7.46(5.61-10.77)^{\dagger}$ & $16.9(8.25-50.00)^{\dagger *}$ & $<0.001$ \\
\hline Testosterone, ng/mL & $4.35(3.50-5.68)$ & $4.26(3.39-5.54)$ & $3.82(2.90-5.24)^{\dagger *}$ & 0.027 \\
\hline Platelet-to-lymphocyte ratio & $0.116(0.094-0.144)$ & $0.120(0.096-0.147)$ & $0.113(0.091-0.147)$ & 0.215 \\
\hline Total prostate volume, $\mathrm{mL}$ & $41.0(31.0-56.9)$ & $32.0(24.3-44.7)^{\dagger}$ & $33.0(25.0-43.0)^{\dagger}$ & 0.928 \\
\hline \multirow[b]{2}{*}{ Patients with PSAs $<10$} & Benign disease & Clinically insignificant cancer & Clinically significant cancer & \multirow[b]{2}{*}{ p-value ${ }^{*}$} \\
\hline & $(\mathrm{n}=\mathbf{8 2 9})$ & $(n=123)$ & $(n=120)$ & \\
\hline \multicolumn{5}{|c|}{ Median (interquartile range) or number of patients (\%) } \\
\hline Age, yr & $66.0(61.0-71.0)$ & $68.0(62.0-73.0)^{\dagger}$ & $69.0(65.0-73.0)^{\dagger}$ & $<0.001$ \\
\hline Body mass index, $\mathrm{kg} / \mathrm{m}^{2}$ & $24.1(22.5-25.9)$ & $24.5(22.7-26.5)$ & $24.0(22.6-25.8)$ & 0.347 \\
\hline Diabetes mellitus & $117(14.1 \%)$ & $24(19.5 \%)$ & $28(23.3 \%)^{\dagger}$ & 0.019 \\
\hline Abnormal DRE finding & $81(9.8 \%)$ & $17(13.8 \%)$ & $25(20.8 \%)^{\dagger}$ & 0.002 \\
\hline PSA, ng/mL & $5.53(4.14-7.27)$ & $6.44(5.03-7.73)^{\dagger}$ & $6.95(5.42-8.17)^{\dagger}$ & $<0.001$ \\
\hline Testosterone, ng/mL & $4.31(3.49-5.66)$ & $4.16(3.29-5.53)$ & $4.07(3.22-5.92)$ & 0.478 \\
\hline Platelet-to-lymphocyte ratio & $0.114(0.093-0.141)$ & $0.119(0.094-0.144)$ & $0.108(0.086-0.127)^{\dagger *}$ & 0.046 \\
\hline Total prostate volume, $\mathrm{mL}$ & $39.0(30.1-51.2)$ & $30.9(23.0-39.9)^{\dagger}$ & $30.2(22.5-37.0)^{\dagger}$ & $<0.001$ \\
\hline \multirow[b]{2}{*}{ Patients with $10 \leq$ PSA $<20$} & Benign disease & Clinically insignificant cancer & Clinically significant cancer & \multirow[b]{2}{*}{ p-value } \\
\hline & $(\mathrm{n}=219)$ & $(\mathbf{n}=37)$ & $(\mathrm{n}=\mathbf{8 8})$ & \\
\hline \multicolumn{5}{|c|}{ Median (interquartile range) or number of patients (\%) } \\
\hline Age, yr & $67.0(61.0-73.0)$ & $72.0(67.5-75.5)^{\dagger}$ & $71.0(67.0-76.0)^{\dagger}$ & $<0.001$ \\
\hline Body mass index, $\mathrm{kg} / \mathrm{m}^{2}$ & $23.8(22.2-25.8)$ & $23.5(20.8-25.3)$ & $23.9(22.5-25.4)$ & 0.572 \\
\hline Diabetes mellitus & $43(19.6 \%)$ & $6(16.2 \%)$ & $15(17.0 \%)$ & 0.805 \\
\hline Abnormal DRE finding & $38(17.4 \%)$ & $6(16.2 \%)$ & $26(29.5 \%)^{\dagger}$ & 0.045 \\
\hline PSA, ng/mL & $13.56(11.35-16.13)$ & $13.38(11.01-15.63)$ & $13.39(11.53-17.36)$ & 0.441 \\
\hline Testosterone, ng/mL & $4.50(3.56-5.68)$ & $4.44(3.68-5.33)$ & $3.79(3.01-4.65)^{\dagger *}$ & 0.005 \\
\hline Platelet-to-lymphocyte ratio & $0.119(0.092-0.153)$ & $0.120(0.100-0.153)$ & $0.121(0.090-0.159)$ & 0.806 \\
\hline Total prostate volume, $\mathrm{mL}$ & $50.7(33.0-73.0)$ & $35.0(29.8-57.3)^{\dagger}$ & $30.1(23.0-38.7)^{\dagger *}$ & $<0.001$ \\
\hline \multirow[b]{2}{*}{ Patients with PSA $\geq 20$} & Benign disease & Clinically insignificant cancer & Clinically significant cancer & \multirow[b]{2}{*}{ p-value } \\
\hline & $(n=64)$ & $(n=13)$ & $(\mathrm{n}=159)$ & \\
\hline \multicolumn{5}{|c|}{ Median (interquartile range) or number of patients (\%) } \\
\hline Age, yr & $69.5(64.0-75.0)$ & $72.0(69.5-73.5)$ & $73.0(68.0-77.0)^{\dagger}$ & 0.018 \\
\hline Body mass index, $\mathrm{kg} / \mathrm{m}^{2}$ & $24.0(21.5-26.0)$ & $24.4(21.6-24.9)$ & $23.9(21.4-25.8)$ & 0.845 \\
\hline Diabetes mellitus & $11(17.2 \%)$ & $2(15.4 \%)$ & $36(22.6 \%)$ & 0.695 \\
\hline Abnormal DRE finding & $12(18.8 \%)$ & $2(15.4 \%)$ & $74(46.5 \%)^{\dagger *}$ & $<0.001$ \\
\hline $\mathrm{PSA}, \mathrm{ng} / \mathrm{mL}$ & $28.21(22.47-37.23)$ & $27.83(22.36-39.28)$ & $64.90(37.20-149.00)^{\dagger \neq}$ & $<0.001$ \\
\hline Testosterone, ng/mL & $4.69(3.33-6.05)$ & $4.45(3.69-5.92)$ & $3.80(2.73-5.25)^{\dagger}$ & 0.045 \\
\hline Platelet-to-lymphocyte ratio & $0.124(0.105-0.165)$ & $0.116(0.089-0.161)$ & $0.115(0.096-0.150)$ & 0.329 \\
\hline Total prostate volume, $\mathrm{mL}$ & $53.6(37.0-82.3)$ & $42.1(24.7-58.2)^{\dagger}$ & $38.9(29.4-48.4)^{\dagger}$ & $<0.001$ \\
\hline
\end{tabular}

Table 2. Comparison of explanatory variables between the patients with benign disease, clinically insignificant cancer, and clinically significant cancer. All variables were presented as median (interquartile range) or the number of patients (\%). DRE digital rectal examination, PSA prostate-specific antigen, $y r$ years. ${ }^{*} \mathrm{p}<0.05$ : comparison of the variables between the groups using the Kruskal-Wallis test, the chi-squared test, or Fisher's exact test, as indicated. ${ }^{\dagger} \mathrm{p}<0.05$ : compared to the group with benign disease using the Mann-Whitney U test, the chi-squared test, or Fisher's exact test, as indicated. ${ }^{\ddagger} \mathrm{p}<0.05$ : comparison between the groups with clinically insignificant cancer and clinically significant cancers using the Mann-Whitney U test, the chisquared test, or Fisher's exact test, as indicated.

that a high PLR is associated with poor oncological outcomes in cancerous conditions. For PCa, a meta-analysis showed a significant correlation between high PLRs and poor overall survival in patients with localized PCa $(\mathrm{HR}=1.72 ; 95 \% \mathrm{CI}: 1.36-2.18, \mathrm{p}<0.001)$ but not in patients with metastatic castration-resistant $\mathrm{PCa}^{9}$. In a 


\begin{tabular}{|c|c|c|c|c|}
\hline & \multirow{2}{*}{$\begin{array}{l}\text { Univariate } \\
\text { OR }(95 \% \mathrm{CI})\end{array}$} & \multirow[b]{2}{*}{ p-value } & \multirow{2}{*}{\begin{tabular}{|l|} 
Multivariate \\
Adjusted OR $(95 \% \mathrm{CI})$
\end{tabular}} & \multirow[b]{2}{*}{$p$-value } \\
\hline & & & & \\
\hline \multicolumn{5}{|l|}{ All patients } \\
\hline Age & $1.100(1.080-1.120)$ & $<0.001$ & $1.102(1.074-1.130)$ & $<0.001$ \\
\hline BMI & $0.960(0.923-0.999)$ & 0.046 & $1.023(0.961-1.090)$ & 0.469 \\
\hline Presence of DM & $1.462(1.093-1.955)$ & 0.010 & $1.537(1.013-2.331)$ & 0.043 \\
\hline Abnormal DRE findings & $3.738(2.845-4.913)$ & $<0.001$ & $1.891(1.241-2.883)$ & 0.003 \\
\hline Serum PSA & $1.050(1.041-1.060)$ & $<0.001$ & $1.050(1.038-1.062)$ & $<0.001$ \\
\hline Serum testosterone & $0.864(0.797-0.938)$ & $<0.001$ & $0.936(0.848-1.033)$ & 0.190 \\
\hline Total prostate volume & $0.975(0.968-0.982)$ & $<0.001$ & $0.948(0.937-0.960)$ & $<0.001$ \\
\hline Platelet-to-lymphocyte ratio & $0.600(0.109-3.296)$ & 0.557 & $0.094(0.003-2.900)$ & 0.176 \\
\hline \multicolumn{5}{|l|}{ Patients with PSA $<10$} \\
\hline Age & $1.075(1.044-1.107)$ & $<0.001$ & $1.081(1.042-1.122)$ & 0.001 \\
\hline BMI & $0.970(0.909-1.036)$ & 0.371 & $1.021(0.929-1.123)$ & 0.662 \\
\hline Presence of DM & $1.751(1.106-2.771)$ & 0.017 & $1.972(1.078-3.608)$ & 0.027 \\
\hline Abnormal DRE findings & $2.293(1.408-3.734)$ & 0.001 & $1.527(0.762-3.060)$ & 0.233 \\
\hline Serum PSA & $1.238(1.126-1.362)$ & $<0.001$ & $1.313(1.162-1.485)$ & $<0.001$ \\
\hline Serum testosterone & $1.003(0.881-1.141)$ & 0.967 & $1.054(0.918-1.210)$ & 0.454 \\
\hline Total prostate volume & $0.945(0.929-0.962)$ & $<0.001$ & $0.934(0.915-0.954)$ & $<0.001$ \\
\hline Platelet-to-lymphocyte ratio & $0.077(0.001-7.058)$ & 0.266 & $0.085(0.000-22.774)$ & 0.387 \\
\hline \multicolumn{5}{|l|}{ Patients with $10<$ PSA $\leq 20$} \\
\hline Age & $1.076(1.039-1.116)$ & $<0.001$ & $1.148(1.08-1.214)$ & $<0.001$ \\
\hline BMI & $0.983(0.901-1.072)$ & 0.696 & $1.101(0.965-1.256)$ & 0.152 \\
\hline Presence of DM & $0.868(0.459-1.641)$ & 0.663 & $0.716(0.291-1.757)$ & 0.465 \\
\hline Abnormal DRE findings & $2.021(1.153-3.542)$ & 0.014 & $1.695(0.737-3.900)$ & 0.214 \\
\hline Serum PSA & $1.055(0.972-1.145)$ & 0.197 & $1.112(0.981-1.259)$ & 0.096 \\
\hline Serum testosterone & $0.724(0.594-0.882)$ & 0.001 & $0.761(0.602-0.961)$ & 0.022 \\
\hline Total prostate volume & $0.945(0.928-0.962)$ & $<0.001$ & $0.929(0.906-0.952)$ & $<0.001$ \\
\hline Platelet-to-lymphocyte ratio & $0.295(0.006-13.600)$ & 0.532 & $0.178(0.000-112.526)$ & 0.600 \\
\hline \multicolumn{5}{|l|}{ Patients with PSA $>20$} \\
\hline Age & $1.054(1.016-1.094)$ & 0.005 & $1.081(1.023-1.143)$ & 0.006 \\
\hline BMI & $0.985(0.907-1.071)$ & 0.727 & $1.016(0.877-1.177)$ & 0.830 \\
\hline Presence of DM & $1.441(0.714-2.909)$ & 0.308 & $2.359(0.741-7.512)$ & 0.146 \\
\hline Abnormal DRE findings & $3.918(2.030-7.562)$ & $<0.001$ & $3.325(1.257-8.795)$ & 0.015 \\
\hline Serum PSA & $1.016(1.008-1.025)$ & $<0.001$ & $1.009(1.002-1.016)$ & 0.016 \\
\hline Serum testosterone & $0.828(0.694-0.988)$ & 0.036 & $0.848(0.676-1.065)$ & 0.157 \\
\hline Total prostate volume & $0.976(0.965-0.988)$ & $<0.001$ & $0.963(0.945-0.982)$ & $<0.001$ \\
\hline Platelet-to-lymphocyte ratio & $0.036(0.000-4.570)$ & 0.178 & $0.004(0.000-4.641)$ & 0.123 \\
\hline
\end{tabular}

Table 3. Univariate and multivariate regression analyses to identify predictors of clinically significant prostate cancer (vs. benign disease + clinically insignificant prostate cancer) at the standard 12-core TRUS-Bx. TRUS-Bx transrectal ultrasound-guided prostate biopsy, $O R$ odds ratio, $B M I$ body mass index, $D M$ diabetes mellitus, $P S A$ prostate-specific antigen, DRE digital rectal examination.

recent meta-analysis, patients with high pretreatment PLRs had higher cancer progression $(\mathrm{HR}=1.62,95 \% \mathrm{CI}$ : $1.20-2.19, \mathrm{p}=0.002)$, overall mortality $(\mathrm{HR}=1.70,95 \% \mathrm{CI}: 1.34-2.15, \mathrm{p}<0.001)$, and cancer-specific mortality $(\mathrm{HR}=2.02,95 \% \mathrm{CI}: 1.24-3.29, \mathrm{p}=0.005)$ than those with low PLRs ${ }^{23}$.

Thus, useful markers as adjuncts to serum PSA levels are needed to avoid unnecessary biopsies or overtreatment while better predicting CSPCa prior to a TRUS-Bx, which currently is the standard modality for diagnosing PCa. Many studies have been conducted on the predictive role of inflammatory markers in the detection of CSPCa at the time of prostate biopsies, but conflicting results have been reported ${ }^{10-14}$. Our objective was to explore the role of pre-biopsy PLRs in predicting CSPCa at standard 12-core TRUS-Bxs in men suspected of PCa based on increased PSA levels or abnormal DRE findings using our large cohort dataset.

In a comparative study of Chinese populations ${ }^{12}$, the PLR was significantly higher in PCa patients than in normal men and patients with benign prostatic hyperplasia (BPH), and was an independent predictor of 3-year mortality in PCa patients. Similar results were reported in an Indonesian study, where significant differences were noted in the PLRs between PCa and BPH patients $(\mathrm{p}=0.02)^{11}$. According to a study by Yuksel et al. in Turkish patients $^{14}$, the PLRs were higher in PCa patients than in BPH patients $(p=0.018)$ but the PLR did not significantly differentiate patients with PCa from those with prostatitis. Murray et al. ${ }^{13}$ found that the pre-biopsy PLR 
was higher in PCa than in non-PCa patients $(\mathrm{p}=0.048)$ but did not discriminate between CSPCa and CISPCa/ benign disease at the initial biopsy in Chilean men with PSA levels of $4-10 \mathrm{ng} / \mathrm{mL}$.

In contrast to these results, our comparative study using large-scale cohort data showed no significant difference in pre-biopsy PLRs among men with benign prostatic disease, CISPCa, and CSPCa at standard 12-core TRUS-Bxs in the entire patient cohort $(\mathrm{p}=0.215)$. These results might be supported by a previous study analyzing the pathological results in men with PSAs between 4 and $10 \mathrm{ng} / \mathrm{mL}^{10}$, which found no significant difference in PLRs between men with benign lesions and those with PCa. There was a significant negative association between ISUP grades and PLRs $(\mathrm{OR}=-0.046 ; 95 \% \mathrm{CI}:-0.089 \text { to }-0.003, \mathrm{p}<0.035)^{10}$. Our data showed that patients with CSPCa, defined as ISUP grade groups of $\geq 2$, had significantly lower PLRs than those with benign disease or CISPCa in a subset of patients with serum PSA levels below $10 \mathrm{ng} / \mathrm{mL}(\mathrm{p}=0.046)$. A possible explanation for these results is that asymptomatic histological inflammation of the prostate is commonly found in men with $\mathrm{BPH}^{24}$. In this study, men with PCa had a significantly smaller prostate than those with benign disease. And it is thought that local inflammation might not be sufficient to alter the systemic markers of inflammation, such as the PLR.

From our results, older age, DM, DRE abnormalities, higher serum PSA levels, and smaller prostate volume were independent predictors of CSPCa at the standard 12-core TRUS-Bx in men with PSA levels of $\geq 3.0 \mathrm{ng} / \mathrm{dL}$ or abnormal DRE findings. In the subset of patients with serum PSA levels of $<10 \mathrm{ng} / \mathrm{mL}$, older age, DM, higher serum PSA levels, and smaller prostate volume were predictive factors of CSPCa. In a study by Li et al. ${ }^{10}$, age and serum PSA levels were independent predictors and positively correlated with the pathological results in men with PSA levels between 4 and $10 \mathrm{ng} / \mathrm{mL}$. According to these results, the pre-biopsy PLR was not a predictor of CSPCa at the standard 12-core TRUS-Bx in men with elevated PSA levels or abnormal DRE findings.

The present study had some limitations. The data were collected retrospectively with a non-randomized design. Second, the enrolled study cohort was a unique racial population. The incidence and prognosis of PCa in Koreans, which could be affected by genetics, environment, and lifestyle such as diet, are different from those of Western populations that may lead to mixed results.

\section{Conclusions}

Based on the analyses of our large-scale cohort data, pre-biopsy PLRs did not differentiate men with benign prostatic disease from those with CISPCa or those with CSPCa at the standard 12-core TRUS-Bx with PSA levels of $\geq 3.0 \mathrm{ng} / \mathrm{mL}$ or abnormal DRE findings. Therefore, the pre-biopsy PLR, as an inflammatory marker, is not a significant predictor of CSPCa. Further large and prospective standardized trials are needed to determine the role of the PLR in predicting CSPCa at the prostate biopsy in men with clinically suspected PCa.

Received: 2 March 2021; Accepted: 22 June 2021

Published online: 09 July 2021

\section{References}

1. Bray, F. et al. Global cancer statistics 2018: GLOBOCAN estimates of incidence and mortality worldwide for 36 cancers in 185 countries. CA Cancer J. Clin. 68(6), 394-424 (2018).

2. Welch, H. G. \& Albertsen, P. C. Reconsidering prostate cancer mortality: The future of PSA screening. N. Engl. J. Med. 382(16), $1557-1563$ (2020).

3. Moyer, V. A. \& U.S. Preventive Services Task Force. Screening for prostate cancer: U.S. Preventive Services Task Force recommendation statement. Ann. Intern. Med. 157(2), 120-134 (2012).

4. Schröder, F. H. et al. Screening and prostate-cancer mortality in a randomized European study. N. Engl. J. Med. 360(13), 1320-1328 (2009).

5. Osses, D. F., Roobol, M. J. \& Schoots, I. G. Prediction medicine: Biomarkers, risk calculators and magnetic resonance imaging as risk stratification tools in prostate cancer diagnosis. Int. J. Mol. Sci. 20(7), 1637 (2019).

6. Lin, C. Y., Lee, M. T., Lin, C. L. \& Kao, C. H. Comparing the staging/restaging performance of $68 \mathrm{Ga}$-labeled prostate-specific membrane antigen and 18F-choline PET/CT in prostate cancer: A systematic review and meta-analysis. Clin. Nucl. Med. 44(5), 365-376 (2019).

7. Sfanos, K. S. \& De Marzo, A. M. Prostate cancer and inflammation: The evidence. Histopathology 60(1), 199-215 (2012).

8. Vignozzi, L. \& Maggi, M. Prostate cancer: Intriguing data on inflammation and prostate cancer. Nat. Rev. Urol. 11(7), 369-370 (2014).

9. Peng, H. \& Luo, X. Prognostic significance of elevated pretreatment systemic inflammatory markers for patients with prostate cancer: A meta-analysis. Cancer Cell Int. 19, 1-18 (2019).

10. Li, G., Shang, Z., Liu, Y., Yan, H. \& Ou, T. The diagnostic values of pretreatment serum inflammation markers and lipoprotein in men with total prostate-specific antigen between 4 and $10 \mathrm{ng} / \mathrm{ml}$. Front. Med. (Lausanne) 7, 576812. https://doi.org/10.3389/fmed. $2020.576812(2020)$.

11. Adhyatma, K. P. \& Warli, S. M. Diagnostic value of platelet-to-lymphocyte ratio in prostate cancer. Open Access Maced. J. Med. Sci. 7, 1093 (2019).

12. Li, F., Hu, H., Gu, S., Chen, X. \& Sun, Q. Platelet to lymphocyte ratio plays an important role in prostate cancer's diagnosis and prognosis. Int. J. Clin. Exp. Med. 8(7), 11746-11751 (2015).

13. Murray, N. P., Fuentealba, C., Salazar, A. \& Reyes, E. Platelet-to-lymphocyte ratio and systemic immune-inflammation index versus circulating prostate cells to predict significant prostate cancer at first biopsy. Turk. J. Urol. 46(2), 115-122 (2020).

14. Yuksel, O. H., Urkmez, A., Akan, S., Yldirim, C. \& Verit, A. Predictive value of the platelet-to-lymphocyte ratio in diagnosis of prostate cancer. Asian Pac. J. Cancer Prev. 16(15), 6407-6412 (2015).

15. Park, J. et al. Low testosterone level is an independent risk factor for high-grade prostate cancer detection at biopsy. BJU Int. 118(2), 230-235 (2016).

16. Epstein, J. I. et al. The 2014 International Society of Urological Pathology (ISUP) consensus conference on Gleason grading of prostatic carcinoma. Am. J. Surg. Pathol. 40(2), 244-252 (2016).

17. Grivennikov, S. I., Greten, F. R. \& Karin, M. Immunity, inflammation, and cancer. Cell 140(6), 883-899 (2010).

18. Finn, O. J. Cancer immunology. N. Engl. J. Med. 358, 2704-2715 (2008).

19. Templeton, A. J. et al. Prognostic role of platelet to lymphocyte ratio in solid tumors: A systematic review and meta-analysis. Cancer Epidemiol. Biomark. Prev. 23(7), 1204-1212 (2014). 
20. Heng, D. Y. et al. Prognostic factors for overall survival in patients with metastatic renal cell carcinoma treated with vascular endothelial growth factor-targeted agents: Results from a large, multicenter study. J. Clin. Oncol. 27(34), 5794-5799 (2009).

21. Gay, L. J. \& Felding-Habermann, B. Contribution of platelets to tumour metastasis. Nat. Rev Cancer. 11(2), 123-134 (2011).

22. Mantovani, A., Allavena, P., Sica, A. \& Balkwill, F. Cancer-related inflammation. Nature 454(7203), 436-444 (2008).

23. Guo, J. et al. Prognostic role of neutrophil to lymphocyte ratio and platelet to lymphocyte ratio in prostate cancer: A meta-analysis of results from multivariate analysis. Int. J. Surg. 60, 216-223 (2018)

24. Vasavada, S. R., Dobbs, R. W., Kajdacsy-Balla, A. A., Abern, M. \& Moreira, D. M. Inflammation on prostate needle biopsy is associated with lower prostate cancer risk: A meta-analysis. J. Urol. 99, 1174-1181 (2018).

\section{Acknowledgements}

This work was supported by the Korea Medical Device Development Fund grant funded by the Korea government (the Ministry of Science and ICT, the Ministry of Trade, Industry and Energy, the Ministry of Health \& Welfare, the Ministry of Food and Drug Safety) (Project Number: 9991006814, KMDF_PR_20200901_0141).

\section{Author contributions}

J.W.L.: Investigation, Writing—original draft. H.J.: Methodology, Supervision. H.S.: Methodology, Supervision. M.C.: Conceptualization, Investigation, Methodology.

\section{Competing interests}

The authors declare no competing interests.

\section{Additional information}

Correspondence and requests for materials should be addressed to M.C.C.

Reprints and permissions information is available at www.nature.com/reprints.

Publisher's note Springer Nature remains neutral with regard to jurisdictional claims in published maps and institutional affiliations.

Open Access This article is licensed under a Creative Commons Attribution 4.0 International nse, which permits use, sharing, adaptation, distribution and reproduction in any medium or format, as long as you give appropriate credit to the original author(s) and the source, provide a link to the Creative Commons licence, and indicate if changes were made. The images or other third party material in this article are included in the article's Creative Commons licence, unless indicated otherwise in a credit line to the material. If material is not included in the article's Creative Commons licence and your intended use is not permitted by statutory regulation or exceeds the permitted use, you will need to obtain permission directly from the copyright holder. To view a copy of this licence, visit http://creativecommons.org/licenses/by/4.0/.

(c) The Author(s) 2021 